\title{
A THICK FILM HYBRID IC AMPLIFIER FOR INDUSTRIAL USE
}

\author{
HIROMI TOSAKI and AKIRA IKEGAMI \\ Production Engineering Research Laboratory, Hitachi Ltd. \\ and \\ TSUTOMU OKAYAMA and YOSHITAKA MATSUOKA \\ Naka Works, Hitachi Ltd.
}

\begin{abstract}
Electronic circuits for industrial uses must satisfy the following requirements: low sensitivity to changes in the surrounding temperature, high reliability, and small size. In the amplifier for a pressure transmitter described here, the temperature dependences of its properties, Zero point and Span, are intensively influenced by TCRs of the resistors used, and by a mismatching of the temperature dependences of the off-set voltages between the two operational amplifier IC chips. As for the thick film resistors, it has been cleared that the DuPont 1700 series resistor pastes are the most suitable:TCRs of less than $+80 \mathrm{ppm} /{ }^{\circ} \mathrm{C}$ can be attained, and the change in resistance of the overglazed and laser trimmed resistors is less than $+0.1 \%$ after 5000 hours at $200^{\circ} \mathrm{C}$. As for the operational amplifier IC chips, their temperature dependences of the off-set voltages are checked individually, utilizing a ceramic carrier containing an operational amplifier IC chip. Then a pair of ceramic carriers, with a minimum mismatching of their temperature dependences, is mounted on a thick film circuit substrate by a $\mathrm{Pb} / \mathrm{Sn}$ solder reflowing. The various transistor chips are divided into three functional blocks, and bonded into three ceramic carriers. Utilization of ceramic carriers in all active devices employed results in sufficient standardization in the characterization of the semiconductor devices and in the hybridizing process.

In the thick film hybrid IC amplifier for a pressure transmitter thus developed, the temperature dependences of Zero point and Span are less than $-0.5 \% \mathrm{FS} / 100^{\circ} \mathrm{C}$, respectively. The drifts of Zero point and Span are less than $\pm 0.1 \%$ FS in the period of 3000 hours of an operating test with DC $24 \mathrm{~V}$ loading at $100^{\circ} \mathrm{C}$.
\end{abstract}

\section{INTRODUCTION}

Thick film technology is widely used in electronic and microelectronic circuits of consumer products, automobiles, and telecommunications for the purpose of high productivity, high reliability, space saving, and cost reduction. In industrial instruments, high precision and high reliability are especially important in widely varying surrounding temperatures. Therefore, components used must have little or no temperature dependences in their properties, and have high stability.

Thick film resistors heretofore have had such a relatively high TCR $\left(> \pm 150 \mathrm{ppm} /{ }^{\circ} \mathrm{C}\right)$ that it has been unsuitable to apply thick film hybrid technology using thick film resistor pastes to electronics of industrial instruments. Recently, however, thick film resistors with a low TCR of $\pm 50 \mathrm{ppm} /{ }^{\circ} \mathrm{C}$ have become commercially available.

Therefore, a two-wire type thick film hybrid IC amplifier for a pressure transmitter using low TCR thick film resistor pastes has been developed.

\section{PRESSURE TRANSMITTER}

Semiconductor detecting systems, transducing sensing parameters into $\mathrm{DC}$ voltage differences or changes in resistance, have been recently extended to many industrial instruments.

In a pressure transmitter described here, a pressure detector consists of a bridge of resistors diffused on a $\mathrm{Si}$ diaphragm. A pressure signal, changing the resistance by piezoelectric effect, is converted into a $\mathrm{DC}$ voltage difference, and the difference is converted into a transmitting signal current of 4.0-20.0 mA, industrially normalized.

Figure 1 shows a schematic diagram of the pressure transmitter. This consists of three functional blocks: a power supplying block, a pressure detecting block, and an amplifying block. 


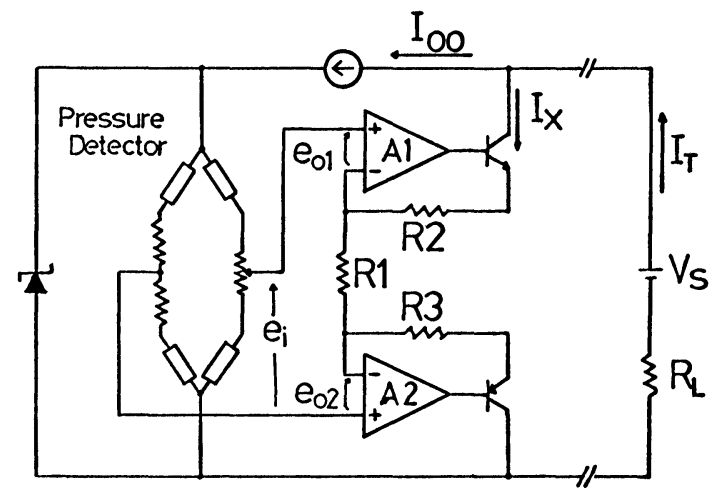

FIGURE 1 Schematic diagram of pressure transmitter.

In this circuit, the transmitting signal current $\left(I_{T}\right)$ is given as follows.

$$
I_{T}=I_{X}+I_{00}
$$

Here, the transfer relation is described by the formula:

$$
I_{T}=(1 / R 1) \cdot\left(e_{i}-e_{01}+e_{02}\right)+I_{00}
$$

where,

$I_{T}$ : transmitting signal current

$I_{x}$ : amplified output current

$I_{00}$ : quiescent current

$R_{1}$ : resistance of reference resistor

$e_{i}$ : output voltage of pressure detector

$e_{01}$ : input off-set voltage of $\mathrm{A} 1$

$e_{02}$ : input off-set voltage of $\mathrm{A} 2$

Figure 2 shows the circuit of a thick film hybrid IC amplifier developed here, consisting of four functional

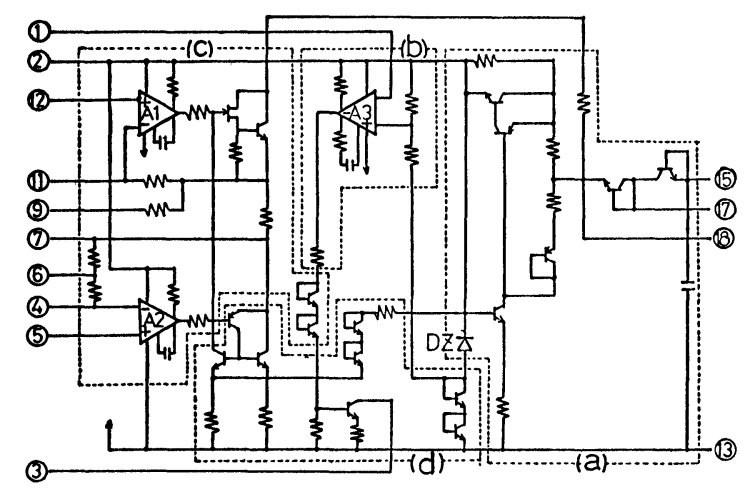

FIGURE 2 Schematic diagram of thick film hybrid IC amplifier. blocks:

a) quiescent current stabilizing and internal power supplying block

b) block regulating current to a pressure detector bridge

c) amplifying block

d) output current limiting block

The transmitting signal current, given by formula (2), varies mainly with the voltage difference produced by a pressure detector. But pressure transmitters are usually placed outdoors; so the transmitting signal current is also influenced by surrounding temperatures and their changes, due to the temperature dependences of off-set voltages of the two operational amplifiers and TCRs of the resistors. Therefore, the following are required to minimize the shift in the transmitting signal current, which is influenced by temperature:

a) using thick film resistors with low TCRs

b) minimizing the difference in temperature dependence between a pair of operational amplifiers

\section{LOW TCR THICK FILM RESISTORS}

For this thick film hybrid IC amplifier, various commercially available thick film resistor pastes with a low TCR of $\pm 50 \mathrm{ppm} /{ }^{\circ} \mathrm{C}$ (value according to their catalogs) are evaluated.

Two sheet resistivity pastes, $100 \mathrm{ohm}$ and $10 \mathrm{k} \mathrm{ohm}$, in four thick film resistor systems are investigated. All of the resistor pastes are fired between $800-900^{\circ} \mathrm{C}$. The electrodes are $\mathrm{Ag} / \mathrm{Pd}$ conductor systems prefired at $850^{\circ} \mathrm{C}$. The resistor size is $1.5 \times 1.5 \mathrm{~mm}$.

Figure 3 shows the relations between the TCRs of $100 \mathrm{ohm}$ sheet resistivity pastes and firing temperature. A TCR of $\pm 50 \mathrm{ppm} /{ }^{\circ} \mathrm{C}$ is attained by EMCA 5512, fired between $840-880^{\circ} \mathrm{C}$, and by Tanaka-Matthey 1102 , fired between $840-860^{\circ} \mathrm{C}$. The TCRs of EMCA 5512 and Tanaka-Matthey 1102 are sensitive to firing

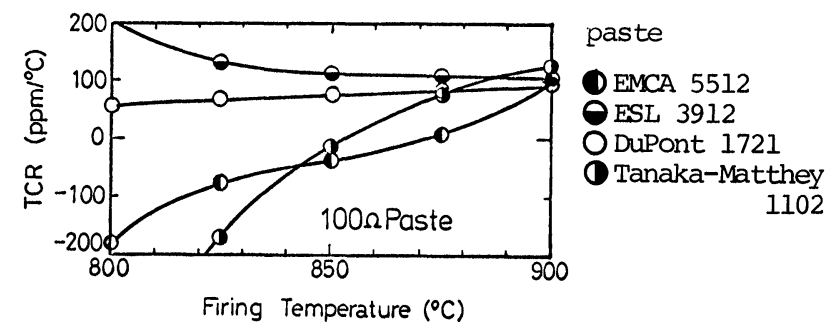

FIGURE 3 TCR vs. firing temperature. 
temperature. But, although the TCR of DuPont 1721 shows $+50-+100 \mathrm{ppm} /{ }^{\circ} \mathrm{C}$, the TCR is very

insensitive to firing temperature.

Figure 4 shows the relations between the TCRs of $10 \mathrm{k} \mathrm{ohm} \mathrm{sheet} \mathrm{resistivity} \mathrm{pastes} \mathrm{and} \mathrm{firing} \mathrm{temperature.}$ A TCR of $\pm 50 \mathrm{ppm} /{ }^{\circ} \mathrm{C}$ is attained by all of the pastes fired between $800-850^{\circ} \mathrm{C}$. In these pastes, the TCR of DuPont 1741 is the most insensitive to firing temperature.

On the basis of the above investigation, DuPont 1700 series resistor pastes are selected to be the thick film resistor paste system of the amplifier. The TCRs of $100 \mathrm{ohm}$ and $10 \mathrm{k}$ ohm sheet resistivity pastes are low, and very insensitive to firing temperature.

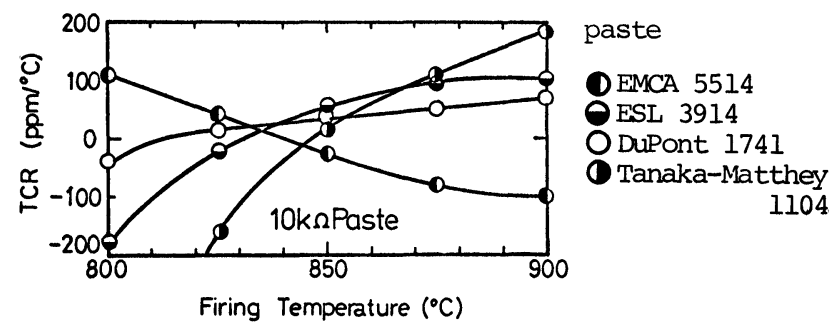

FIGURE 4 TCR vs. firing temperature.

\section{THICK FILM RESISTORS APPLIED}

Three thick film resistor pastes, $100 \mathrm{ohm}, 10 \mathrm{k} \mathrm{ohm}$, and $100 \mathrm{k} \mathrm{ohm}$ sheet resistivity pastes, are applied for a thick film hybrid IC amplifier. They are DuPont 1700 series resistor pastes: ${ }^{1}$

100 ohm sheet resistivity-DuPont 1721

$10 \mathrm{k}$ ohm sheet resistivity-DuPont 1741

100k ohm sheet resistivity-DuPont 1751

The three are investigated in detail.

\subsection{TCR vs. Firing Temperature}

Figure 5 shows the relations between the TCRs of the three pastes and firing temperature. The TCR of the $100 \mathrm{k}$ ohm sheet resistivity paste has a relatively large temperature dependence, but at $850^{\circ} \mathrm{C}$ the TCR is $+40 \mathrm{ppm} /{ }^{\circ} \mathrm{C}$. The other two pastes have less firing temperature dependences than the $100 \mathrm{k}$ ohm sheet resistivity paste. Deviations of the TCRs of the three are smallest at $850^{\circ} \mathrm{C}$. Here the TCR of the $100 \mathrm{ohm}$ sheet resistivity paste is $+80 \mathrm{ppm} /{ }^{\circ} \mathrm{C}$, and that of the $10 \mathrm{k} \mathrm{ohm}$ sheet resistivity paste is $+20 \mathrm{ppm} /{ }^{\circ} \mathrm{C}$.

According to these results, the three resistor pastes can be fired at the same temperature: $850^{\circ} \mathrm{C}$.

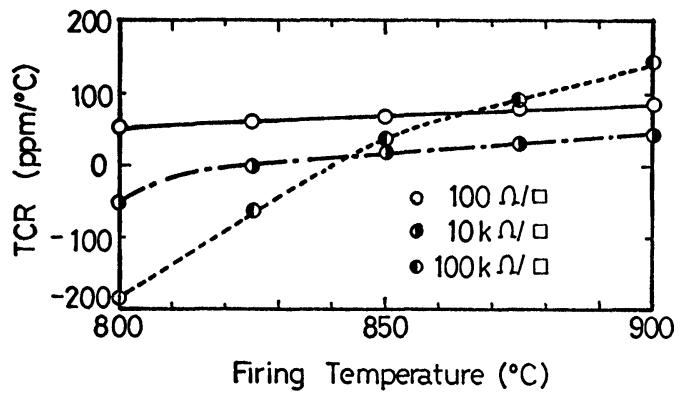

FIGURE 5 TCR vs. firing temperature.

\subsection{TCR vs. Resistor Length}

Figure 6 shows the relations between the TCRs of the three pastes and resistor length. The resistor width is fixed at $1.5 \mathrm{~mm}$. The TCR of the $100 \mathrm{ohm}$ sheet resistivity paste decreases as the resistor lengthens, but that of a $4.0 \mathrm{~mm}$ long resistor is over $+50 \mathrm{ppm} /{ }^{\circ} \mathrm{C}$. The TCRs of the $10 \mathrm{k} \mathrm{ohm}$ and $100 \mathrm{k}$ ohm sheet resistivity pastes increase as the resistors lengthen. That of the $10 \mathrm{k} \mathrm{ohm}$ sheet resistivity paste is within $\pm 50 \mathrm{ppm} /{ }^{\circ} \mathrm{C}$ of the range of $0.5-4.0 \mathrm{~mm}$. For $100 \mathrm{k} \mathrm{ohm}$ sheet resistivity paste, a TCR within a range of $\pm 50 \mathrm{ppm} /{ }^{\circ} \mathrm{C}$ is attained for lengths less than $1.5 \mathrm{~mm}$. These results are used to select low TCR thick film resistors' dimensions.

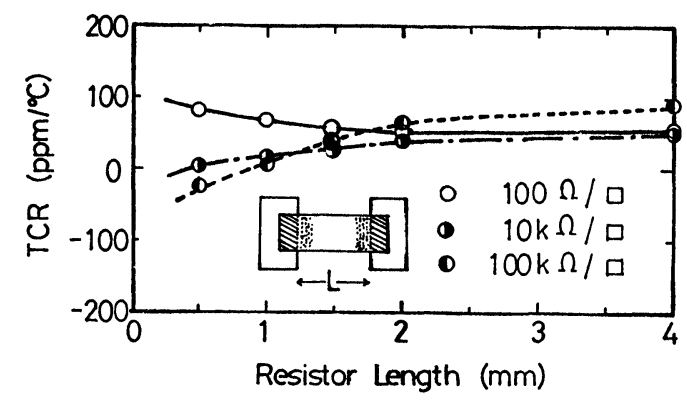

FIGURE 6 TCR vs. resistor length.

\subsection{Stability}

Resistors formed for a thick film hybrid IC amplifier are examined at $100^{\circ} \mathrm{C}, 150^{\circ} \mathrm{C}$, and $200^{\circ} \mathrm{C}$ over a period of 5000 hours. All of them are over-glazed. Table I shows changes in resistance under the test. Changes in trimmed resistors are larger than those in non-trimmed ones, but the change in resistance at $200^{\circ} \mathrm{C}$ after 5000 hours is less than $+0.1 \%$. 
TABLE I

Change in resistance under temperature storage

\begin{tabular}{lllll}
\hline \multirow{2}{*}{$\begin{array}{l}\text { Sheet } \\
\text { resistivity } \\
(\mathrm{ohm} / \square)\end{array}$} & Trimming & \multicolumn{3}{c}{ Change in resistance (\%) } \\
\cline { 3 - 5 } & & $100^{\circ} \mathrm{C}$ & $150^{\circ} \mathrm{C}$ & $200^{\circ} \mathrm{C}$ \\
\hline 100 & none & +0.01 & +0.03 & +0.09 \\
& trimmed & +0.03 & +0.05 & +0.09 \\
$10 \mathrm{k}$ & none & +0.02 & +0.02 & +0.05 \\
& trimmed & +0.04 & +0.04 & +0.09 \\
$100 \mathrm{k}$ & none & +0.01 & +0.01 & +0.02 \\
& trimmed & +0.01 & +0.01 & +0.03 \\
\hline
\end{tabular}

Under the temperature cycling test $\left(-55-+150^{\circ} \mathrm{C}\right.$, 24 cycles/day), change in resistance is less than $+0.1 \%$ after 3000 cycles.

These results show that the thick film resistors applied have good stability and are adaptable for the thick film hybrid IC amplifier for the pressure transmitter.

\section{CERAMIC CARRIER}

In a thick film hybrid IC amplifier for a pressure transmitter, ceramic carriers ${ }^{2-4}$ are used in the following ways:

1) Operational amplifier IC chips must be checked individually, not only room temperature but also in a wide temperature range $\left(-40-+100^{\circ} \mathrm{C}\right)$, with little mismatching of off-set voltage temperature dependences between the two IC chips. Checking an IC chip is usually difficult, so a method utilizing a ceramic carrier containing an IC chip is applied. This method makes finding the characteristics of an individual IC chip easy. Failure to check temperature dependence impairs the performance of the thick film hybrid IC amplifier.

2) Eighteen transistors are used in this amplifier. They are divided into three functional blocks (a, c, and $\mathrm{d}$ in Figure 2). All of the transistor chips in each block are attached to a ceramic carrier. Thus, many transistors are compactly collected in the three ceramic carriers.

Figure 7 shows transistor chips attached to ceramic carriers. The ceramic carrier is $10.0 \times 10.0 \mathrm{~mm}$ in size, with 23 terminals on the sides and the back. Inside the bottom of the ceramic carrier, transistor chips are attached on separated Au metalized pads. After Au wire bonding and Kovar cap sealing, they are examined by a He leak test.

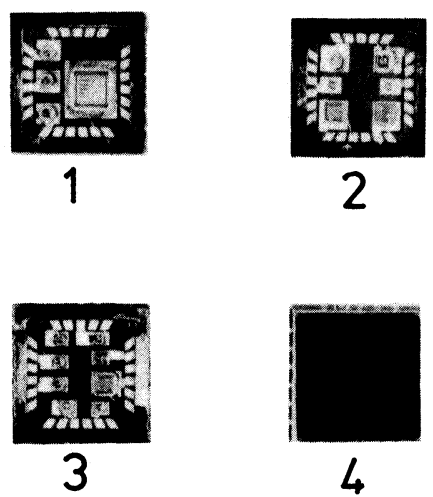

FIGURE 7 Ceramic carriers containing transistor chips. 1) for the amplifying block (4 chips); 2 ) for the quiescent current stabilizing and internal power supplying block ( 6 chips); 3 ) for the output current limiting block ( 8 chips); 4) hermetically sealed with Kovar cap.

Utilization of ceramic carriers in all active devices used results in sufficient standardization in the characterization of the devices and in the hybridizing process.

\section{FABRICATION}

A thick film hybrid IC amplifier for a pressure transmitter has been experimentally fabricated through the following steps (Figure 8).

1) Formation of first layer conductors: $\mathrm{The} \mathrm{Ag} / \mathrm{Pd}$ system conductor paste (DuPont 9061) is printed on a $53.0 \times 50.0 \mathrm{~mm} \mathrm{Al} \mathrm{O}_{3}$ substrate, and fired at $850^{\circ} \mathrm{C}$.

2) Printing of resistors: The three resistor pastes, DuPont 1721, DuPont 1741, and DuPont 1751, are printed. The resistors are designed to $70 \%$ of the desired resistances, because resistance deviation after firing is about $\pm 30 \%$.

3) Printing of dielectrics: A low dielectric paste (DuPont 9429) is printed for insulators of crossovers.

4) Printing of second layer conductors: The conductor paste (DuPont 9061) is printed for crossovers.

5) Firing: Printed resistors, dielectrics, and second layer conductors are fired at $850^{\circ} \mathrm{C}$.

6) Formation of overglaze: A lead-borosilicate glass paste is printed and fired at $530^{\circ} \mathrm{C}$, for overglaze on resistors and glass dams.

7) Trimming of resistors: All resistors are trimmed by a YAG laser trimming system. As a result, resistances are adjusted within $\pm 1.0 \%$ of the desired values. 


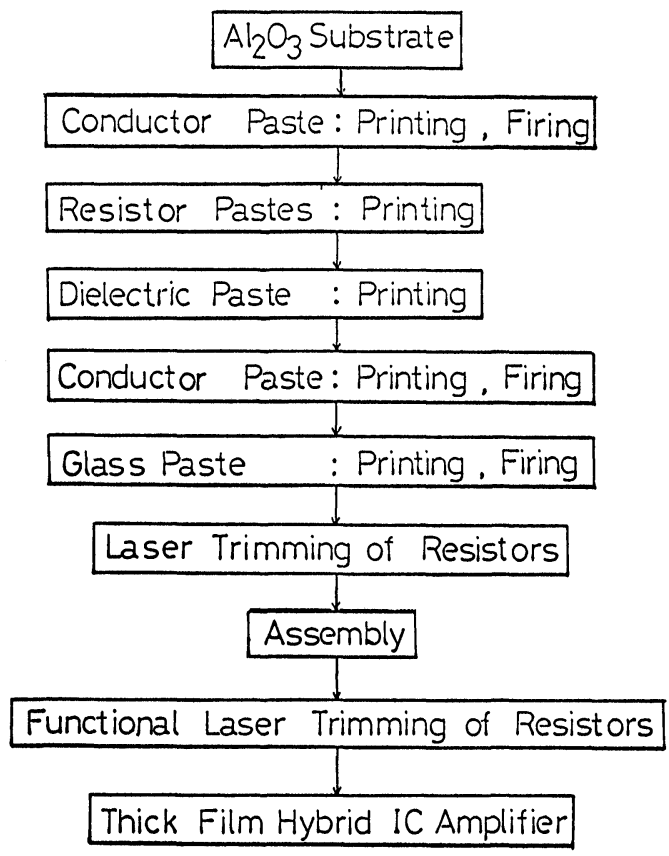

FIGURE 8 Fabrication process of thick film hybrid IC amplifier for pressure transmitter.

8) Assembly: $\mathrm{A} \mathrm{Pb} / \mathrm{Sn}$ eutectic solder paste is printed on a thick film circuit substrate. Six ceramic carriers, a high precision Zener diode, and four ceramic chip capacitors are placed on the proper positions. All the components are connected to a thick film circuit by reflowing the solder at $230{ }^{\circ} \mathrm{C}$.

9) Functional trimming: An assembled thick film hybrid IC amplifier is connected to a signal voltage inputting circuit and a transmitting signal current adjusting circuit. Functional laser trimming adjusts the following:

a) minimum output current to $3.60 \pm 0.05 \mathrm{~mA}$

b) maximum limiting current to $23.0 \pm 0.2 \mathrm{~mA}$

c) supplying voltage of a pressure detector circuit to $1.05 \pm 0.02 \mathrm{~V}$

A completed thick film hybrid IC amplifier for a pressure transmitter is shown in Figure 9.

\section{PROPERTIES OF THICK FILM HYBRID IC AMPLIFIER FOR PRESSURE TRANSMITTER}

In a pressure transmitter, the pressure signal is converted to an industrially normalized current of $4.0-20.0 \mathrm{~mA}$. Zero point is the current $\left(I_{0 \%}\right)$ adjusted

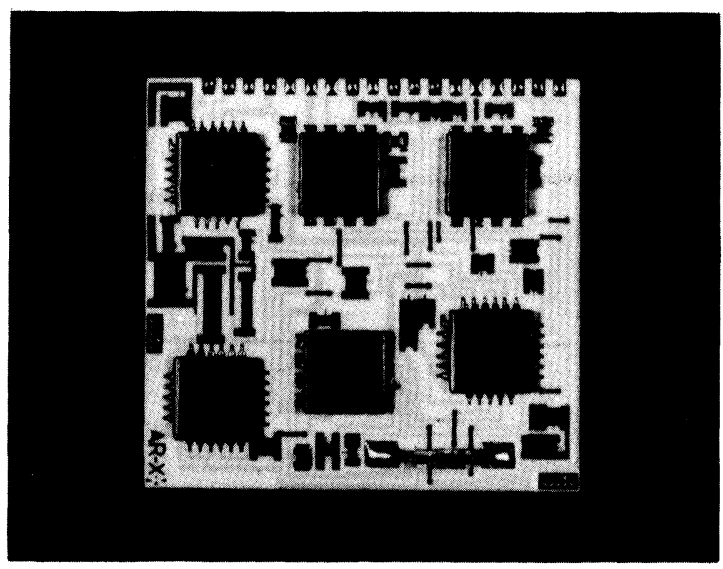

FIGURE 9 Thick film hybrid IC amplifier for pressure transmitter $(53.0 \times 50.0 \mathrm{~mm}$ in size $)$.

to $4.0 \mathrm{~mA}$, and Full scale point is the current $\left(I_{100 \%}\right)$ adjusted to $20.0 \mathrm{~mA}$. Span is the current variation of $16.0 \mathrm{~mA}, I_{100 \%}-I_{0 \%}$.

\subsection{Temperature Dependences of Amplifier Properties}

Figure 10 shows the relations between Zero point shift and the surrounding temperature. Zero point shift is the deviation of the transmitting signal current adjusted to $4.0 \mathrm{~mA}$ at $25^{\circ} \mathrm{C}$. The temperature dependence is less than $-0.3 \% \mathrm{FS} / 100^{\circ} \mathrm{C}$.

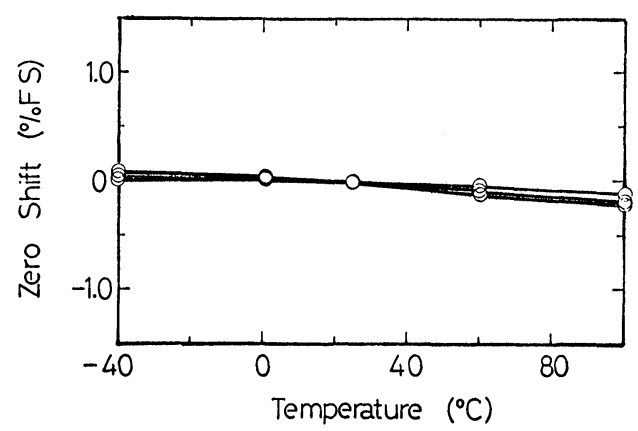

FIGURE 10 Zero point shift vs. temperature.

Figure 11 shows the relations between Span shift and the surrounding temperature. Span shift is the deviation of the transmitting signal current variation adjusted to $16.0 \mathrm{~mA}$ at $25^{\circ} \mathrm{C}$. The temperature dependence is less than $-0.5 \% \mathrm{FS} / 100^{\circ} \mathrm{C}$.

These temperature dependences of Zero point and Span are as little as the amplifier can be applied to a practical use. 


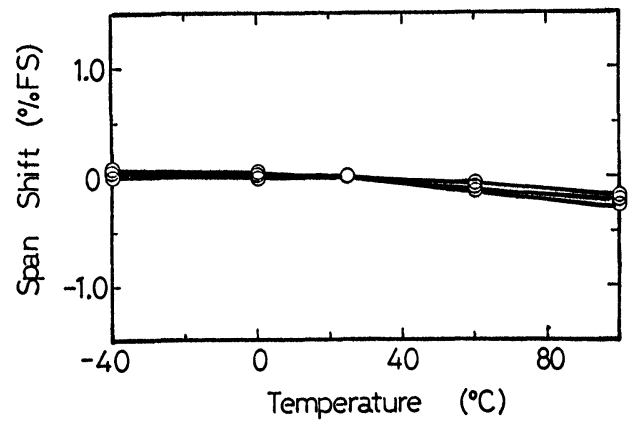

FIGURE 11 Span shift vs. temperature.

\subsection{Power Supplying Voltage Dependence}

The pressure transmitter is powered by DC $24 \mathrm{~V}$. In a two-wire type amplifier connected in line to an electric meter (maximum resistance $600 \mathrm{ohm}$ ), the supplying voltage that powers the amplifier directly decreases to DC $12 \mathrm{~V}$ in extreme cases. Therefore, the amplifier must operate at DC $12 \mathrm{~V}$ at least, and the power supplying voltage dependence of a transmitting current must be negligible.

Figure 12 shows the relations between the transmitting current and the power supplying voltage. The current is normalized at DC $24 \mathrm{~V}$ at each temperature. The power supplying voltage dependence of the transmitting current is little and negligible in a practical use.

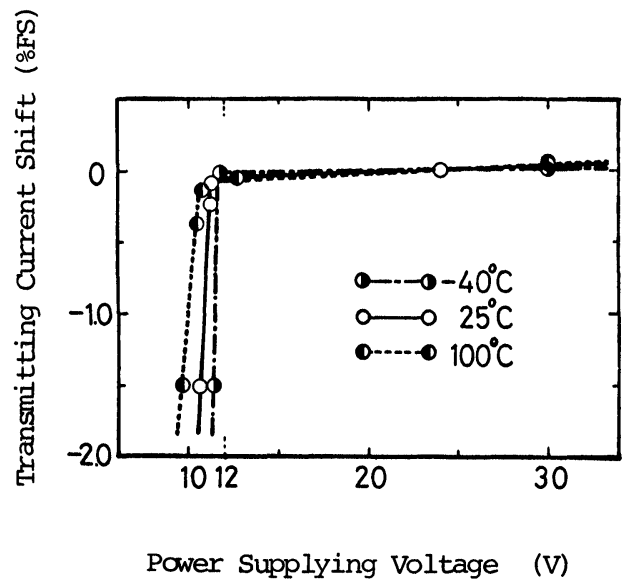

FIGURE 12 Transmitting current shift vs. power supplying voltage.

\subsection{Stability}

Figure 13 shows long term drifts of Zero point and Span in an operating test with DC $24 \mathrm{~V}$ loading at

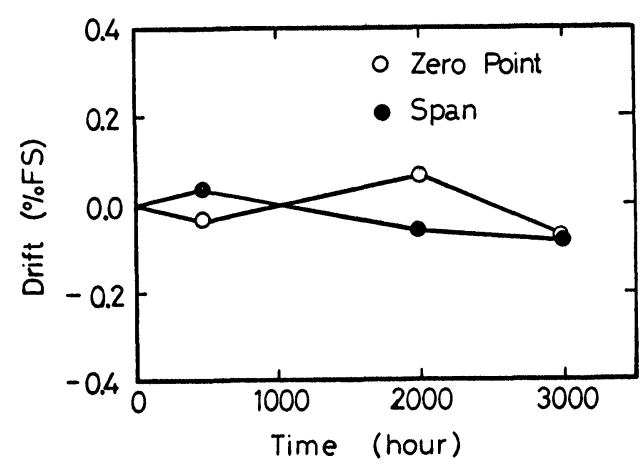

FIGURE 13 Drifts of Zero point and Span.

$100^{\circ} \mathrm{C}$. In a period of 3000 hours the drifts are less than $\pm 0.1 \%$ FS.

As stated above, this thick film hybrid IC amplifier for a pressure transmitter thus developed has high precision and high stability.

\section{CONCLUSION}

A thick film hybrid IC amplifier suitable for a pressure transmitter has been described.

DuPont 1700 series thick film resistor pastes are suitable for this amplifier because of their low TCRs and high stability.

Utilization of ceramic carriers in active devices employed, such as the operational amplifier and transistor chips, results in sufficient standardization in the characterization of the devices and in the hybridizing process.

An experimentally fabricated thick film hybrid IC amplifier has properties which can be suitably applied to a pressure transmitter.

\section{ACKNOWLEDGEMENTS}

The authors wish to thank M. Ai and T. Isogai for their helpful suggestions based on a pressure transmitter system, M. Shimazoe for his assistance to prepare ceramic carriers, M. Nakamura, N. Niizaki, K. Abe, Y. Akiba, and H. Arima, for their useful discussions.

\section{REFERENCES}

1. J. R. Larry et al., "A New High Stability Resistor System," Proc. of the 27th ECC, pp 348-357 (May, 1977).

2. Calvin Adkins and Marvin Silverstein, "A New Approach to Hybrid Packing Using Ceramic Chip Carriers," Proc. of the 26th ECC, pp 300-303 (April, 1976). 
3. Jon S. Prokop et al., "Advances in Microelectronic Subsystems with Chip Carriers," Insulation/Circuit, pp 23-26 (Aug., 1979).
4. Subash Khadpe, "Design and Cost Considerations for Ceramic Chip Carrier Packing of Active Devices," Proc., of ISHM, pp 270-273 (1979). 

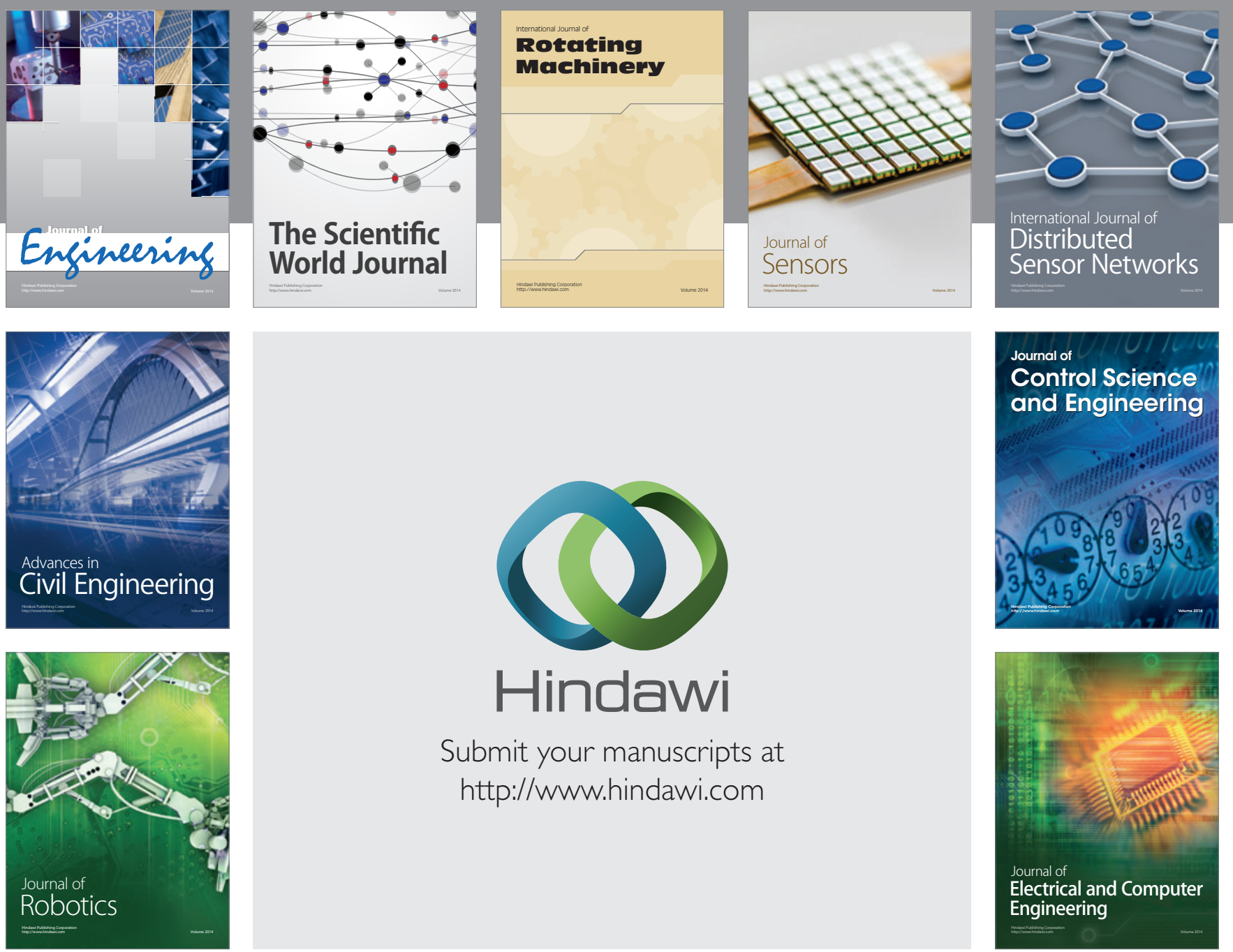

Submit your manuscripts at

http://www.hindawi.com
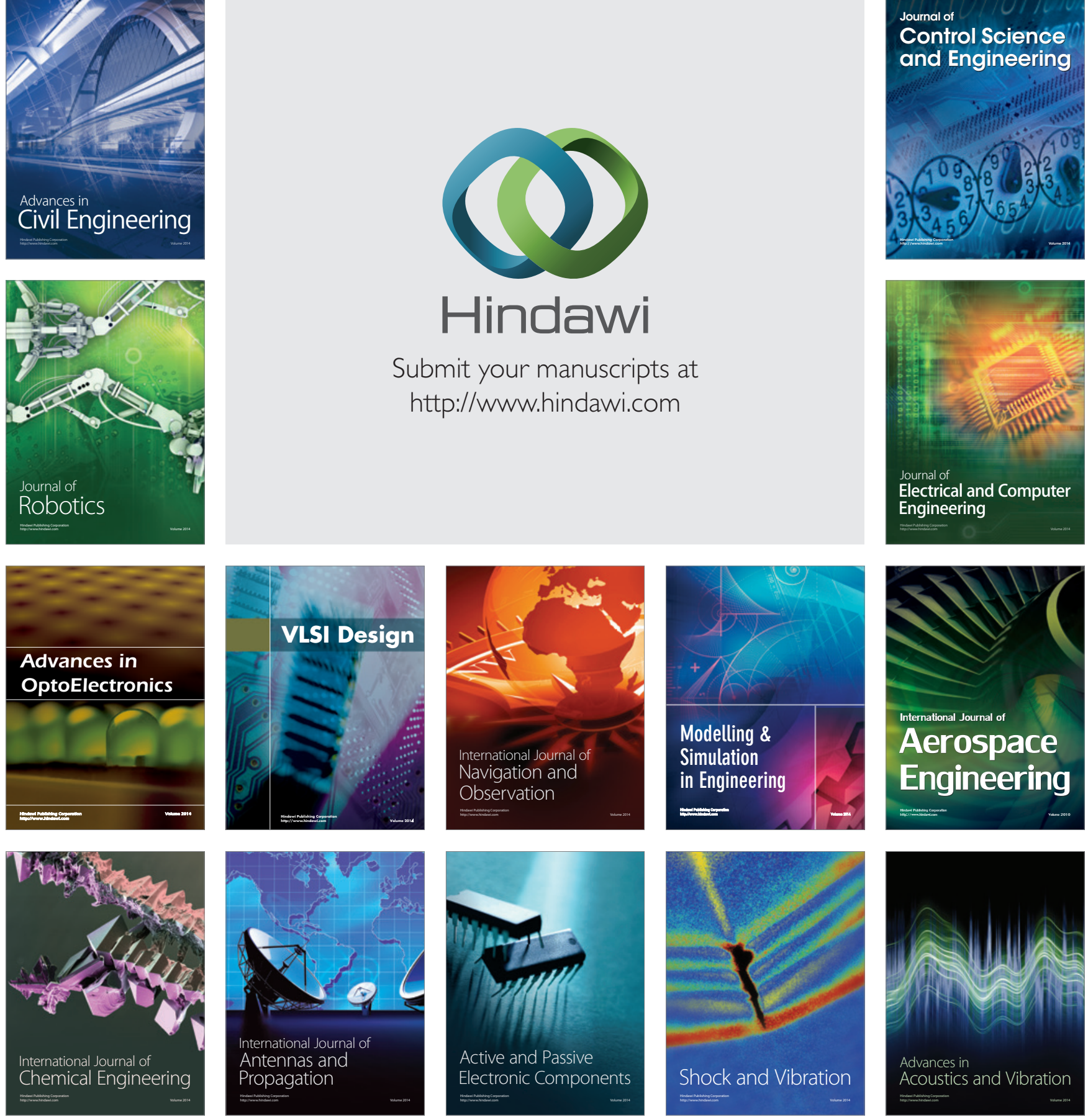